\title{
OS PROJETOS DE REDUÇÃO DE EMISSÕES DO DESMATAMENTO E DA DEGRADAÇÃO FLORESTAL (REDD)
}

\author{
Ana Paula Dalla Corte ${ }^{1}$, Carlos Roberto Sanquetta ${ }^{2}$, Flávio Felipe Kirchner ${ }^{3}$, Nelson Carlos Rosot ${ }^{2}$ \\ ${ }^{1}$ Eng $^{\mathrm{a}}$. Florestal, Dr ${ }^{\mathrm{a}}$., Depto. de Ciências Florestais, UFPR, Curitiba, Paraná, Brasil - anapaulacorte@ gmail.com \\ 1'Eng. Florestal, Dr., Depto. de Ciências Florestais, UFPR, Curitiba, Paraná, Brasil - sanquetta@ufpr.br; ncrosot@ufpr.br \\ ${ }^{3}$ Eng. Florestal, Dr., Instituto de Ecologia Terrestre, Curitiba, Paraná, Brasil - kirchner@ufpr.br \\ Recebido para publicação: 13/09/2010 - Aceito para publicação: 21/11/2011
}

\begin{abstract}
Resumo
O desmatamento e degradação de florestas nativas contribuem para o aquecimento global e as mudanças climáticas. Aproximadamente, $30 \%$ das emissões mundiais de gases de efeito estufa (GEE) são provenientes dessa modalidade, demonstrando urgência em alternativas para redução desses gases. Este trabalho tem por objetivo apresentar uma visão sobre o estado da arte acerca dos projetos de redução das emissões pelo desmatamento e pela degradação florestal (REDD). Para tanto, é realizada uma abordagem sobre a questão da regulamentação desse assunto nas negociações internacionais, bem como são apresentadas iniciativas de desenvolvimento de projetos REDD no mundo, na América Latina e no Brasil. Também são apresentados o marco referencial dos projetos REDD e alternativas de monitoramento dos mesmos. Para o desenvolvimento de projetos REDD, foi apresentada a metodologia proposta pela Aliança Clima, Comunidade e Biodiversidade (CCBA). Por fim, realizou-se uma discussão sobre as principais críticas internacionais e desafios dos projetos REDD, bem como de algumas iniciativas de investimentos nos mesmos.

Palavras-chave: Supressão de vegetação; emissões GEE; florestas.
\end{abstract}

\begin{abstract}
The projects for reducing deforestation emission and forest degradation (REDD). Deforestation and forest degradation are two important factors that contribute to global warming and climate changes. Approximately $30 \%$ of the total emissions of greenhouse effect gases are originated by deforestation and forest degradation, which emphasizes urgency of alternatives for their mitigation. This research aims to present an overview of current state of emission reducing projects from deforestation and forest degradation (REDD). In order to that, it performs an approach on the issue of regulation in relation to international negotiations, as well as it presents initiatives for development of REDD in the world, in Latin America and Brazil. Furthermore, it presents the reference point of REDD projects as well as alternatives for their monitoring. Due to REDD projects development, it presents the methodology proposed by the Alliance Climate, Community and Biodiversity (CCB). At last, it improves a discussion about the main international critics and challenges for REDD projects, as well as about some investments in these initiatives.
\end{abstract}

Keywords: Deforestation; emission GHG; forest.

\section{INTRODUÇÃO}

Estima-se que o desmatamento nas florestas tropicais e a sua degradação representem entre 25 e $30 \%$ das emissões mundiais de carbono produzidas por ações antrópicas durante os anos 90 (MOUTINHO; SCHWARTZMAN, 2005). O desmatamento global é estimado em 13 milhões de hectares por ano no período de 1990-2005 (FAO, 2005). O Painel Intergovernamental sobre Mudança do Clima (IPCC) estima que as emissões totais somente nos anos 90 tenham atingido $5,8 \mathrm{GtCO}_{2} /$ ano. Segundo a Agência Europeia do Ambiente (AEA) (2009), os dados mais recentes mostram que as emissões globais de $\mathrm{CO}_{2}$ aumentaram quatro vezes mais depressa desde 2000 do que na década anterior. Esse aumento está relacionado a diversos setores de emissões, como energia, processos industriais, tratamento de resíduos, agropecuária e mudança de uso do solo e florestas. Entre outros setores, o IPCC apontou a redução ou 
prevenção do desmatamento global como uma opção de mitigação de impacto imediato e de curto prazo em relação à liberação de carbono para a atmosfera.

Visando reduzir as emissões de Gases de Efeito Estufa (GEE) globais, o Protocolo de Quioto estipulou metas de redução de emissões para um primeiro período de compromisso (2008-2012) aos países classificados como Anexo 1. Com a entrada em vigor desse Protocolo no ano de 2005, os países Anexo 1 começaram a ter que atingir as metas estipuladas pelo mesmo (UNFCCC, 2004).

Alguns países do Anexo 1, como França, Grécia, Suécia e Reino Unido, já alcançaram as suas metas de redução de emissões em 2006. Áustria, Bélgica, Finlândia, Alemanha, Irlanda, Luxemburgo, Holanda e Portugal projetaram que iriam atingir as suas metas, mas as projeções da Dinamarca, Itália e Espanha indicam que eles não conseguirão atingir os seus objetivos na redução das emissões (AEA, 2009).

Durante as Conferências das Partes sobre as Mudanças Climáticas (COP), cada vez tem-se discutido a possibilidade de inserção formal das florestas nativas dentro da referida Convenção Quadro das Nações Unidas para o Clima (UNFCCC) para o pós-2012, ou seja, após a expiração do atual acordo global pautado no Protocolo de Quioto. Dessa forma, esforços vêm sendo feitos com vistas a apoiar os países maiores detentores de florestas para que eles venham a ter subsídios para a redução de desmatamento e degradação de suas florestas.

Esse assunto já vem sendo discutido desde 2005, quando da Conferência das Partes $n^{\circ} 11$, que aconteceu em Montreal. Inicialmente se falava em projetos de Redução de Emissões do Desmatamento (RED) e na sequência o termo expandiu-se para a inclusão da questão da conservação e manejo florestal sustentável, respectivamente REDD+ e REDD++.

Alguns países ainda não possuem metas de redução de emissões de GEE no primeiro período de compromisso (2008-2012), como é o caso do Brasil. Entretanto, as emissões provenientes de mudanças no uso da terra no Brasil são responsáveis por cerca de 75\% das emissões totais de GEE deste país (MCT, 2004). Assim, toda a emissão proveniente de combustíveis fósseis e fontes emissoras corresponde apenas a um quarto das emissões brasileiras, a qual é minoritária se comparada às emissões devidas ao desmatamento, queima de biomassa e conversão de ecossistemas naturais para outras formas de uso do solo.

Grande parte dessas mudanças está localizada na Amazônia Brasileira. Conforme o INPE (2008), o Programa de Monitoramento da Amazônia (PRODES) indicou uma taxa anual de corte raso na Amazônia Legal brasileira para o período 2007-2008 de $11.968 \mathrm{~km}^{2}$, o que representaria um aumento de 3,8\% em relação ao mesmo período de 2006-2007. Em levantamento amostral, constatou-se que, no período 2007-2008, 38\% dos alertas desse programa corresponderam a corte raso, $48 \%$ a degradação florestal e $14 \%$ a alertas não confirmados.

Conforme Angelsen (2008), a Redução das Emissões do Desmatamento e Degradação Florestal (REDD) tem como ideia central premiar indivíduos, comunidades, projetos e países que consigam reduzir os GEE provenientes da degradação e desmatamento oriundos das florestas. Esse autor complementa que o REDD tem o potencial para produzir grandes cortes nas emissões de GEE a baixo custo e no curto prazo e, ao mesmo tempo, contribuir para a redução da pobreza, promovendo o desenvolvimento sustentável.

Assim, as comunidades podem também construir suas próprias condições de adaptação aos efeitos das mudanças climáticas para se prepararem para os efeitos das mudanças climáticas globais. Projetos bem conceituados também contribuem para a conservação da biodiversidade, por meio da restauração e proteção de ecossistemas naturais, protegendo espécies animais e vegetais da extinção e mantendo um ambiente natural, resiliente e produtivo à humanidade. Com planejamento e implementação eficientes, todos estes resultados positivos podem ser alcançados de maneira economicamente efetiva.

O objetivo deste trabalho é apresentar uma visão sobre o estado da arte dos projetos de redução das emissões pelo desmatamento e pela degradação florestal (REDD).

\section{A situação do REDD no âmbito da convenção do clima (UNFCCC)}

As discussões acerca da inclusão do tema "conservação de florestas" dentro das negociações das mudanças climáticas já vêm sendo realizadas desde o início das tratativas que resultaram no Protocolo de Quioto. Muitas divergências de posições sobre a inclusão desse tema surgiram e, por diversas vezes, acabou sucumbindo qualquer possibilidade de inclusão delas no âmbito das negociações e acordos internacionais a esse respeito. A explicação para tais divergências sempre recaiu em questões de soberania nacional e preocupações de ordem técnica (por exemplo, como monitorar, na época, tais projetos). 
Desde 2005, quando da Conferência das Partes de Montreal, as discussões acerca da REDD têm ganho muitos adeptos, inclusive com o consenso da necessidade de atenção para esse tema, tendo em vista a importância e a significância nas emissões mundiais.

As expectativas sobre as decisões tocantes aos REDD eram grandes para a COP-15, que aconteceu em 2009 em Copenhague, na Dinamarca. Entretanto, mais uma vez, as negociações foram tumultuadas e não houve grande avanço em relação a um posicionamento com regras claras e mecanismos de inclusão do REDD dentro do Protocolo de Quioto ou novo acordo climático global. Dentro do chamado Acordo de Copenhague, como ficou conhecido o documento resultante dessa reunião, são citados dois aspectos atinentes ao REDD, sendo eles:

22. Países em desenvolvimento podem tomar ações de mitigação, incluindo aquelas apoiadas, no setor florestal, ao reduzir emissões por desmatamento ou degradação florestal, conservação de estoques florestais de carbono, manejo sustentável de floresta e reforço de estoques florestais de carbono; estas ações devem ser medidas e relatadas de acordo com a decisão -/CP.15 (REDD mais) $e$ outras decisões a serem adotadas na Conferência das Partes. (...)

36. Fundos adequados, adicionais, novos, mensuráveis e ampliados devem ser providos para países em desenvolvimento, de acordo com Artigo 4, parágrafos 3, 4, 5, 8 e 9 da Convenção, para permitir e apoiar uma ação fortalecida em mitigação, incluindo REDD mais, adaptação, desenvolvimento de tecnologia e transferência e capacitação, para implantação avançada da Convenção após 2012.

Assim, pode-se dizer que não existe ainda uma regulamentação clara acerca desses projetos dentro do atual arcabouço de acordos sobre o clima e, dessa forma, entre tantas iniciativas em prol de tal tema, espera-se que o próximo acordo a ser firmado nas próximas COPs crie efetivamente incentivos significativos para remunerar os países detentores de florestas pelos serviços climáticos prestados por elas.

\section{As iniciativas de projetos de redd no mundo}

Wertz-Kanounnikoff e Kongphan-Apirak (2009) fizeram um levantamento sobre iniciativas de projetos voluntários de REDD na África, Ásia e América Latina, entre novembro e dezembro de 2008, e as informações coletadas foram atualizadas até maio 2009. Nesse levantamento, foram encontradas mais de 100 iniciativas de REDD no mundo, sendo 44 ações efetivas de redução, 65 atividades de demonstração de intenção e 12 atividades em que o carbono não é o objetivo explícito. Conforme esses autores, a Indonésia possui a maior parte das intenções de projetos, sendo que a maioria delas ainda encontra-se em fase de planejamento (68\%).

O CIFOR (2008) está desenvolvendo um estudo comparativo sobre os projetos de REDD que terá como objetivo identificar as iniciativas de projetos REDD em nível nacional e subnacional. São 5 países da América Latina, África e Ásia que estão incluídos no estudo. O acompanhamento do número de projetos identificados pelo CIFOR pode ser efetuado através do site http://www.forestsclimatechange.org/survey.html. Nesse mesmo site, é possível observar a taxa de desmatamento para cada país entre os anos 2000 e 2005, informada pela FAO (2005). O trabalho do CIFOR em relação ao REDD enfoca uma ampla gama de questões, de metodologias técnicas até a governança no nível nacional e políticas internacionais relacionadas às negociações climáticas (PARKER et al., 2008).

Conforme apresentado por CIFOR (2008), serão analisados, no curto prazo, cerca de 20 projetos de REDD realizados nos países. Essa avaliação está sendo desenvolvida com o objetivo de observar a eficácia, eficiência e equidade dos projetos. Quatorze países candidatos têm sido propostos para inclusão no estudo: Bolívia, Brasil, Guiana, Panamá e Peru, na América Latina, a República Democrática do Congo, Gana, Tanzânia e Zâmbia, na África, e Indonésia, Laos, Nepal, Papua Nova Guiné e Vietnã, na Ásia. Os pesquisadores estão coletando dados de projetos REDD antes de sua efetiva implantação, em seu início e após três a quatro anos da sua implementação, visando uma comparação entre eles. Esse acompanhamento permitirá que as alterações nos estoques de carbono, bem-estar humano e de outros resultados possam ser investigados.

Algumas são as iniciativas de projetos REDD submetidos à Aliança Clima, Comunidade e Biodiversidade, conhecida como CCBA. Até janeiro de 2010, haviam sido submetidos 41 projetos a essa instituição (Figura 1). Entre esses projetos, quatro eram brasileiros, sendo que em agosto de 2011 esse número passou para sete. 
O Banco Mundial, através da criação do Fundo Cooperativo para o Carbono nas Florestas (FCPF) de assistência aos países em desenvolvimento, vem recebendo e financiando projetos de REDD no mundo. Da mesma maneira, apoia projetos para conservar e manejar sustentavelmente as florestas e realizar inventários de carbono nas mesmas, cujas informações poderão ser aplicadas em projetos de REDD. Esse fundo foi concebido após a COP-13 (Bali, Indonésia) e entrou em operação em junho de 2008. Inicialmente, o FCPF prestou assistência técnica e capacitação em países membros do Banco Mundial nas zonas tropicais na África, Ásia, América Latina e Caribe. Esse fundo apoiou diversos países a criarem seus cenários de referência para a comparação com possíveis projetos de REDD. Em novembro de 2009, 37 países da Ásia, América Latina e África, entre os quais o Brasil não figura, foram selecionados para participar e elaborar o Project Idea Note, denominado de PIN, sendo os projetos revisados por um comitê de participantes e assessores técnicos independentes. Esses países são chamados de participantes REDD e recebem doações para desenvolver propostas de projetos, que devem conter um histórico sobre as causas dos desmatamentos e degradação florestal, um esquema para o manejo do REDD+ nacional, o termo de referência para definição do cenário de referência das emissões que embasam as taxas históricas de emissões e as emissões evitadas e futuras, o estabelecimento de um sistema de monitoramento e a estratégia de adoção nacional para o REDD.

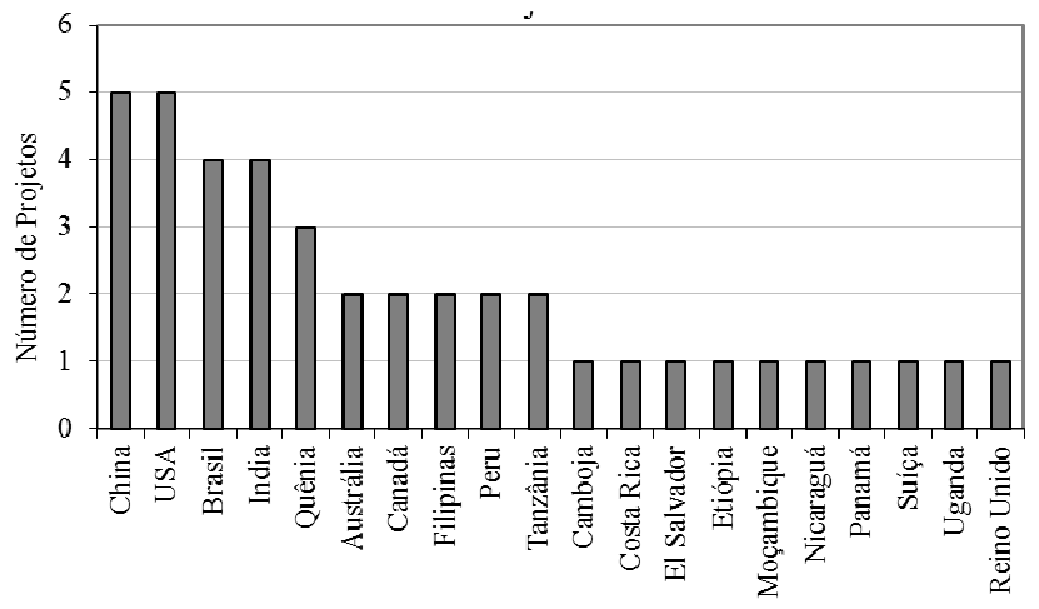

Figura 1. Número de projetos submetidos ao CCBA até janeiro de 2010.

Figure 1. Number of projects submitted to CCBA to January 2010.

\section{As iniciativas de projetos na América Latina e Brasil}

Cenamo et al. (2009) mencionam que na América Latina existem 17 projetos de REDD, que totalizam 521.206.421 t CO $2 \mathrm{e}$ de redução de emissões (Figura 2). Esse autor comenta que o Brasil tem a maior quantidade de projetos (7) e também a maior quantidade de reduções de emissões, totalizando 277,6 milhões de $\mathrm{t} \mathrm{CO}_{2 \mathrm{e}}$. Em seguida vem o Equador, com apenas 1 projeto de 190 milhões de $\mathrm{CO}_{2 \mathrm{e}}$, seguido da Guatemala, com 3 projetos que totalizam 23,1 milhões de t $\mathrm{CO}_{2 \mathrm{e}}$. Depois, com uma quantidade menos expressiva de redução de emissões, aparecem o Paraguai (1 projeto com 13 milhões de $\mathrm{CO}_{2 \mathrm{e}}$ ), o Peru (4 projetos com 11,7 milhões de t $\mathrm{CO}_{2 \mathrm{e}}$ ) e a Bolívia (1 projeto com 5,8 milhões de $\mathrm{C}_{2 \mathrm{e}}$ ).

Dentre os projetos listados por Cenamo et al. (2009), vale destacar alguns exemplos de recentes projetos de REDD brasileiros:

- Ecomapuá - Projeto de REDD na Amazônia, desenvolvido pelo setor privado, pela Ecomapuá Conservação Ltda.;

- Projeto de REDD Gênesis, desenvolvido pelo Instituto Ecológica em parceria com as instituições CantorCO $\mathrm{C}_{2}$ e CarbonFund.org;

- Projeto de REDD na Reserva Juma, desenvolvido pela Fundação Amazônia Sustentável, Governo do Amazonas, Marriott Hotel e Instituto de Conservação e Desenvolvimento Sustentável do Amazonas (IDESAM);

- Projeto Suruí, desenvolvido pelo IDESAM e ACT-Brazil. 
Os projetos de REDD no Brasil possuem propostas de duração entre 15 a 44 anos, tendo 6.783.204 hectares de área destinadas à finalidade de redução de emissões pelo desmatamento ou degradação florestal (Tabela 1). Os projetos de REDD do Brasil estão situados nos estados do Acre, Pará, Tocantins, Amazonas, Rondônia, Mato Grosso e Paraná. O maior projeto brasileiro em termos de redução de emissões é o projeto Juma. Esse projeto foi implementado pela Fundação Amazonas Sustentável (FAS) em parceria com o Governo do Estado do Amazonas, a rede de hotéis Marriott International e o Instituto de Conservação e Desenvolvimento Sustentável do Amazonas (IDESAM). O projeto foi validado pela Aliança Clima, Comunidade e Biodiversidade (CCBAA) e também pela empresa alemã TÜV-SUD. Essa validação garante que o projeto cumpre com boas práticas e assegura a entrega de benefícios reais em termos de clima, biodiversidade e comunidade (CENAMO et al., 2009).

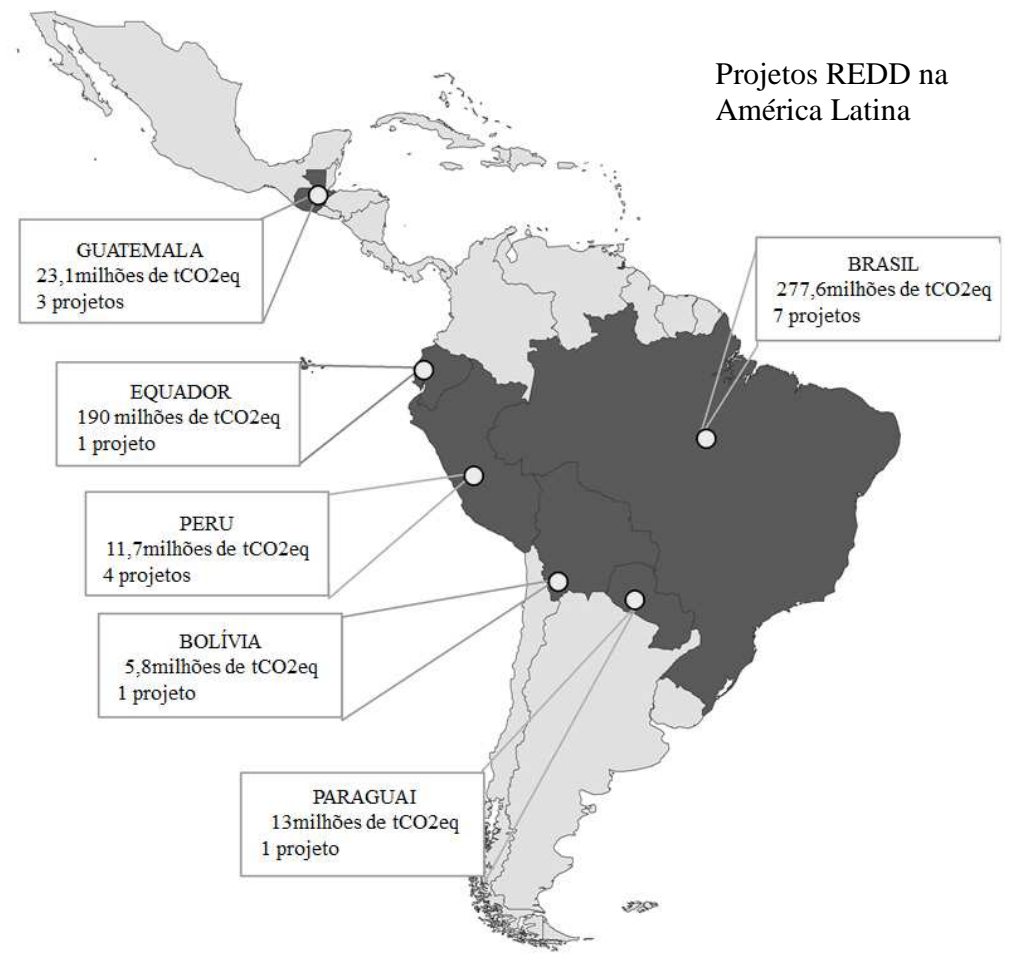

Figura 2. Projetos de REDD existentes na América Latina. Fonte: Adaptado de Cenamo et al. (2009). Figure 2. REDD projects in Latin America.

Tabela 1. Resumo dos projetos de REDD no Brasil.

Table 1. Résumé of REDD projects in Brazil.

\begin{tabular}{lccccc}
\hline Projetos & $\begin{array}{c}\text { Taxa de } \\
\text { desmatamento } \\
\text { usada no } \\
\text { Projeto }\end{array}$ & $\begin{array}{c}\text { Período } \\
\text { (anos) }\end{array}$ & $\begin{array}{c}\text { Redução de } \\
\text { emissões total } \\
\text { (milhões tCO }\end{array}$ & $\begin{array}{c}\text { Área do } \\
\text { projeto (ha) }\end{array}$ & Estado \\
\hline Projeto Acre & $0,42 \%$ & 15 & 62,50 & 5.800 .000 & Acre \\
Ecomapuá & $0,84 \%$ & 20 & 6,00 & 94.171 & Pará \\
Genesis & $0,67 \%$ & 20 & 0,06 & 1.076 & Tocantins \\
Transamazônica & $4,80 \%$ & 10 & 3,14 & 31.745 & Pará \\
Juma & $1,41 \%$ & 44 & 189,00 & 589.612 & Amazonas \\
Antonina & $0,09 \%$ & 40 & 0,38 & 18.600 & Paraná \\
Suruí & $0,37 \%$ & 44 & 16,50 & 248.000 & Rondônia e Mato Grosso \\
\hline
\end{tabular}

Fonte: Adaptado de Cenamo et al. (2009). 
Ainda Cenamo et al. (2009) comentam que existiam outros cinco projetos brasileiros em fase inicial de concepção, sendo eles:

- Projeto Piloto de REDD no noroeste do Mato Grosso, com 10,5 milhões de hectares, formados por $82 \%$ de remanescentes florestais, desenvolvido pela TNC e Instituto Centro Vida (ICV);

- Projeto de REDD Calha Norte no Pará, com 7,4 milhões de hectares, desenvolvido pela Secretaria de Meio Ambiente do Estado do Pará (SEMA-PA), Conservation International - Brazil e Instituto do Homem e Meio Ambiente da Amazônia (IMAZON);

- Apuí Verde, com 12.000 hectares, no estado do Amazonas, desenvolvido pelo IDESAM;

- Projeto Sócio-Ambiental Xingu no estado do Mato Grosso, desenvolvido pela Aliança da Terra (Land Alliance) e IPAM;

- Projeto Piloto em São Félix do Xingu, no estado do Pará, desenvolvido pelo Governo do Estado, Prefeitura Municipal e TNC.

CIFOR (2011) identificou várias outras iniciativas de projetos REDD no Brasil, dentre as quais se destacam no Acre o projeto Iniciativa da Rede de Carbono Florestal (WWF), no Pará o projeto do Rio Guamã e o projeto Mapuera. Em Rondônia o projeto Cinta Larga. No Mato Grosso, são várias as iniciativas citadas, entre as quais o projeto de REDD+ do Alto Teles Pires, o projeto Demonstrativo de REDD no Mato Grosso, o projeto Instituto Ouro Verde, o projeto Sumidouro de Carbono: Projeto de Reflorestamento na Amazônia, o projeto Poço de Carbono Juruena, o projeto de Desmatamento Evitado Prolifico Foundation e o projeto de Reflorestamento na Região do Xingu.

\section{Marco referencial para os projetos REDD}

Apesar de ainda não existir um consenso ou documento formal para apresentação de projetos REDD, algumas discussões a esse respeito já iniciaram. Serão apresentados os principais aspectos comuns dos projetos e em seguida, em outro item, será apresentado um modelo de seções necessárias para projetos de REDD proposto pelo CCBAA. Para Parker et al. (2008), os 4 blocos que embasam os projetos de REDD são: escopo, nível de referência, distribuição e financiamento (Figura 3). Dentro do escopo está apresentado o que está sendo considerado dentro do projeto, ou seja, as atividades consideradas elegíveis para a geração de redução de emissões de GEE para o REDD. Entre as atividades que poderão fazer parte deles estão: Redução de emissões por desmatamento (RED), Redução de emissões por desmatamento e degradação (REDD) ou Redução de emissões por desmatamento e degradação e incremento dos estoques de carbono (REDD+).

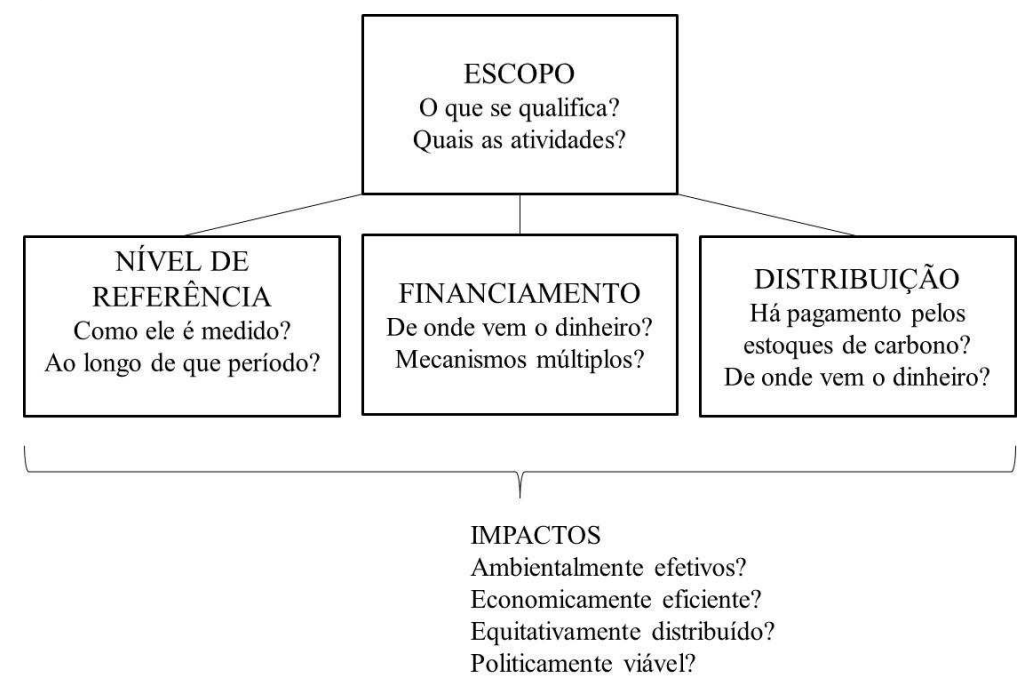

Figura 3. Esquema dos blocos que embasam os projetos de REDD.

Figure 3. Blocks that support the REDD projects.

Fonte: Adaptado de PARKER et al. (2008) 
O nível de referência refere-se à linha de base utilizada para o projeto de REDD, cujas opções são: linha de base histórica, linha de base histórica ajustada (Figura 4a) ou linha de base projetada (Figura 4b). A abordagem da taxa histórica de emissões tem sido utilizada pela maior parte dos projetos de REDD apresentados até o momento. Entretanto, existe ainda muita polêmica em relação a essa adoção, tendo em vista as seguintes situações: não retratam de forma representativa os processos de desmatamento ou degradação florestal em países onde eles são recentes; tornar-se-iam um forte estímulo para os países com taxas de desmatamentos históricas altas; inexistem informações confiáveis acerca dessas taxas.

Ainda dentro desse bloco, existe a necessidade de especificação da escala que está sendo adotada, sendo subnacional, nacional ou global. Fica claro que os níveis de referência servem para definir o cenário do que é chamado de business as usual (prática comum) dentro de uma escala de tempo definida. Dessa forma, podem ser utilizados para a avaliação da adicionalidade dos projetos em relação às reduções de emissões de GEE com a implementação de um possível projeto (PARKER et al., 2008).

O próximo bloco citado por Parker et al. (2008) trata da distribuição, ou seja, como os benefícios das reduções deverão ser distribuídos ou alocados a países com florestas "em pé". Entre as opções existentes, temos o Mecanismo de Redistribuição e o Mecanismo Adicional. A maioria das propostas defende incentivos ou compensações diretamente alinhadas com as ações da própria Parte. Outras propostas sugerem que alguns desses benefícios devem fluir a Partes diferentes daquelas que geraram as reduções de emissões, através de um mecanismo de distribuição.

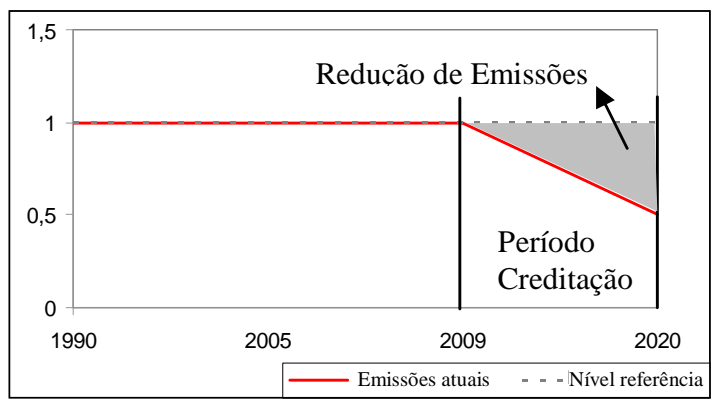

(a)

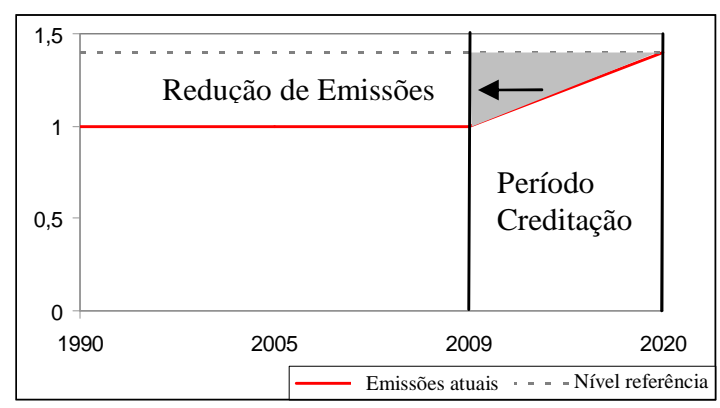

(b)

Figura 4. (a) Linha de base histórica - Reduções de emissões que ocorrem abaixo da linha de base histórica são contabilizadas como adicionais. (b) Linha de base histórica ajustada - Reduções de emissões abaixo desse novo nível de referência são contabilizadas como adicionais.

Figure 4. a) Historical baseline - Current emissions reduction below the historical basis are considered additional. (b) Adjusted historical baseline - Emissions reduction below this new reference level are considered additional.

Por fim, temos o bloco que trata das questões de financiamento dos projetos REDD, ou seja, quem pagará por esse serviço que a floresta estará executando em prol das mudanças climáticas. As fontes de financiamento referem-se explicitamente aos recursos que seriam usados para incentivar reduções de emissões num mecanismo de REDD, em contraste a outros financiamentos voltados à capacitação ou conservação de estoques de carbono. As opções existentes para tal situação são: doações voluntárias, vinculadas ao mercado, mercado direto ou abordagem por fases. $\mathrm{O}$ financiamento para o REDD pode ser agrupado em três categorias principais: um fundo voluntário, um mecanismo de mercado direto ou híbrido/vinculado ao mercado (PARKER et al., 2008).

\section{Monitoramento, publicação e verificação}

Para o monitoramento dos projetos de REDD, não basta apenas garantir o não desmatamento e a não degradação florestal. Devem-se monitorar também aspectos dos estoques de carbono, da biodiversidade, aspectos sociais, de linha de base e também aspectos de vazamentos dos projetos.

O monitoramento do desmatamento, em geral, é realizado através de técnicas de sensoriamento remoto e fotogrametria aérea, pelas quais, através de uma análise temporal, avalia-se a evolução da cobertura florestal. Entretanto, a degradação florestal é um processo difícil de ser observado e registrado somente através dessas técnicas, necessitando de muita acuidade visual do interpretador ou algoritmo de detecção de mudanças. 
O monitoramento dos estoques de carbono pode ocorrer de algumas formas, sendo principalmente avaliados através das opções retratadas na figura 5. A opção 1 apontada na figura 5a considera a mudança nos estoques de carbono como sendo a diferença entre o estoque em dois momentos distintos pelo tempo decorrido entre eles. A opção 2 apontada na figura $5 \mathrm{~b}$ considera a mudança nos estoques de carbono como a diferença entre o ganho anual em carbono e a perda anual em carbono.

Os projetos precisam se preocupar também com o monitoramento da linha de base, ou seja, com o cenário de referência cujos "ganhos" em termos de redução de emissões serão comparados. Para tanto, deverão ser comparadas às taxas anuais de desmatamento de cada país/região.

Uma outra preocupação que deve estar retratada nesses projetos trata-se do vazamento do projeto, ou seja, as iniciativas para evitar as emissões de carbono (degradação ou desmatamento) em um determinado local poderiam apenas desviar o desmatamento ou degradação para outro foco na região. Esse argumento foi um dos principais motivos para os acordos internacionais de REDD terem fracassado até o momento. Dessa forma, o projeto precisará contemplar medidas para que seja confirmado que o vazamento não está acontecendo.

Ademais, vários aspectos, como biodiversidade de espécies de fauna e flora, deverão ser levados em consideração e garantidos pelo projeto, bem como aspectos sociais que envolvam a comunidade envolvida pelo projeto.

\begin{tabular}{|l|l|l|}
\hline $\begin{array}{l}\text { Opsção 1- Metodologia Diferença de Estoque de } \\
\text { carbono no } \\
\text { ano 1 }\end{array}$ & \multicolumn{1}{|c|}{$\begin{array}{l}\text { Estoque de } \\
\text { carbono no } \\
\text { ano 2 }\end{array}$} &
\end{tabular}

(a)

(b)

Figura 5. (a) Opção 1 de monitoramento do carbono. (b) Opção 2 de monitoramento do carbono.

Figure 5. (a) Option 1 for carbon monitoring. (b) Option 2 for carbon monitoring.

\section{Seções para a composição dos projetos conforme modelo proposto pela CCBAA}

Os projetos de REDD ainda não possuem regulamentação oficial no secretariado executivo da ONU, o UNFCCC, nem mesmo consenso sobre como se dará a inclusão deles nas negociações do Protocolo de Quioto. Muitas discussões acerca dessa inclusão em um mecanismo formal de redução de emissões de GEE vem acontecendo e, paralelamente ao mecanismo formal de Quioto, algumas iniciativas de mercados voluntários (não formais) foram surgindo, entre os quais os mercados VCS e CCBAA, que possuem em seus escopos o desenvolvimento de projetos de REDD. No Brasil, existem sete iniciativas de projetos REDD conforme o padrão CCBA verificados ou em fase de verificação.

O mercado voluntário CCBAA tem um padrão que apresenta as bases metodológicas para desenvolvimento dos projetos. Conforme menciona CCBAA (2008), citado por Corte (2010), o documento do projeto é composto por 5 seções, sendo elas: $1^{\mathrm{a}}$ - Seção Geral; $2^{\mathrm{a}}$ - Seção Clima; $3^{\mathrm{a}}-$ Seção Comunidades; $4^{\mathrm{a}}$ - Seção Biodiversidade; e 5a - Seção de "Nível Ouro".

No tópico G1 (Condições Originais da Área do Projeto) são descritas características como localização do projeto e parâmetros físicos básicos (ex.: solos, geologia, clima), os tipos e condições da vegetação dentro da área do projeto, os limites da área e da zona do projeto, estoques atuais de carbono dentro das áreas do projeto, descrição das comunidades localizadas na zona do projeto, descrição do uso da terra atual e dos direitos legais e tradicionais de propriedades e informações gerais sobre a biodiversidade. 
No tópico G2 (Projeções de Linha de Base) é feita a descrição das condições esperadas na área do projeto na ausência das atividades do projeto. Os impactos da implementação do projeto serão comparados com esse cenário de referência "sem projeto". Para tanto, deverão ser descritas algumas características, como o cenário de uso da terra mais provável na ausência do projeto, os benefícios esperados com o projeto que não teriam ocorrido na ausência do mesmo, o cálculo das mudanças nos estoques de carbono associadas com o cenário de referência "sem projeto" (nos projetos de REDD devem ser citadas as taxas de desmatamento e/ou degradação adotadas) e uma explanação sobre como o cenário de referência "sem projeto" afetaria as comunidades e a biodiversidade na zona do projeto.

No tópico G3 (Concepção e Objetivos do Projeto) deve-se apresentar um resumo do projeto, descrever as atividades, apresentar o mapa de localização, citar os possíveis riscos naturais e antropogênicos e os benefícios esperados ao clima, demonstrar que a concepção do projeto inclui medidas para garantir a manutenção ou melhoria da biodiversidade e descrever as medidas para manter e incrementar os benefícios de clima, entre outros.

No caso do G4 (Capacidade de Gestão e Boas Práticas), deve-se apresentar as informações do proponente do projeto, as habilidades técnicas específicas que serão necessárias para a implementação do projeto, o plano de orientação e treinamento para os empregados do projeto e pessoas relevantes das comunidades, demonstrar que serão dadas oportunidades igualitárias às comunidades para preenchimento das vagas de trabalho, listar todas as leis e regulamentos relevantes ao projeto, avaliar extensivamente situações e cargos que representem riscos substanciais à segurança dos trabalhadores e documentar a saúde financeira das organizações envolvidas.

No tópico G5 (Status Legal e Direitos de Propriedade) deve-se apresentar uma lista de todas as leis e regulamentos relevantes nos âmbitos nacionais e locais do país-sede do projeto, bem como comprovar que o projeto tem a aprovação das autoridades apropriadas. Demonstrar, através de consultas e acordos documentados, que o projeto não transgredirá qualquer propriedade privada, comunitária ou governamental. Demonstrar que o projeto não requer a realocação involuntária de pessoas ou atividades importantes para o meio de vida e cultura das comunidades, assim como identificar qualquer atividade ilegal que possa trazer impactos ao clima, comunidades e biodiversidade. Demonstrar que os proponentes do projeto têm titularidade clara e incontestável sobre os direitos de carbono.

O tópico CL1 (Impactos Líquidos Positivos ao Clima) se beneficiará do trabalho aqui descrito, tendo em vista que precisará apresentar o balanço líquido nos estoques de carbono devido à implementação das atividades do projeto, que é igual às mudanças nos estoques de carbono com o projeto menos as mudanças nos estoques de carbono sem o projeto. Caso existam outros GEE envolvidos, deverá ser estimado também o balanço líquido nas emissões de $\mathrm{GEE}$ não- $\mathrm{CO}_{2}$, $c 0 m o \mathrm{CH}_{4} \mathrm{e} \mathrm{N}_{2} \mathrm{O}$, no cenário com e sem projeto.

No item CL2 (Impactos Climáticos fora da Área do Projeto - "Vazamentos"), deverão ser listados os tipos de vazamentos esperados e estimados os potenciais aumentos nas emissões de GEE fora da área do projeto, assim como a estratégia de mitigação dos mesmos.

No item CL3 (Monitoramento dos Impactos Climáticos), que também se beneficiará deste trabalho, deverá ser descrita a metodologia que se pretende adotar para realizar o acompanhamento das áreas e do crescimento ou supressão da vegetação. Esse plano de monitoramento deverá ser implementado dentro de seis meses a partir da data do início do projeto ou dentro de doze meses a partir da validação nos Padrões CCBA.

Nos tópicos CM1, CM2 e CM3, deverão ser apresentados os impactos às comunidades dentro e fora do projeto e o plano de como se pretende acompanhar, ao longo do período de duração do projeto, a sua relação com a comunidade.

Nos tópicos B1, B2 e B3, o projeto precisará comprovar que irá gerar impactos líquidos positivos à biodiversidade, demonstrar que avaliaram os impactos negativos sobre a biodiversidade e propuseram um plano de monitoramento para a biodiversidade.

Os tópicos GL1, GL2 e GL3 são opcionais e indicam se o projeto irá fornecer apoio significativo na assistência às comunidades e/ou biodiversidade, para que estas se adaptem aos impactos das mudanças climáticas. Esses tópicos visam demonstrar o real benefício que o projeto trará, além do clima, para as populações envolvidas e para o ambiente.

\section{Principais críticas e os desafios dos projetos REDD}

Os projetos de REDD vêm sofrendo diversas críticas em relação ao seu papel frente às mudanças climáticas. Principalmente pelo fato e temor de que os países do Anexo 1 aproveitem essa oportunidade de cumprir as metas internacionais sem que tenham que cortar suas emissões através de substituição tecnológica ou através de mecanismos de captura de GEE. Dirigentes de países que não possuem metas, 
como, por exemplo, Brasil, China e Bolívia, já se manifestaram desfavoráveis a essa situação de que projetos de REDD possam servir para que grandes emissores não façam seus trabalhos de casa. Esse argumento também vem sendo usado por diversas instituições não governamentais como motivo para não apoiar iniciativas de REDD, tendo em vista o medo de que esses créditos, que poderiam vir de projetos de REDD, façam com que o preço da tonelada de carbono baixe significativamente e, assim, torne os projetos de mudanças tecnológicas inviáveis.

Segundo Anderson (2009), a própria definição do que constitui uma floresta é um assunto controvertido nas negociações internacionais sobre REDD. A questão técnica mais complexa, porém, envolve a degradação florestal. Em contraste com o desmatamento, há diferentes graus de degradação florestal, mas como ela ocorre abaixo do dossel (conjunto das folhas e galhos das árvores), é mais difícil de detectar. Da mesma forma, enquanto o desmatamento é geralmente através de corte raso, a degradação é frequentemente temporária e muitas vezes reversível. Por exemplo, os sinais de exploração madeireira altamente seletiva desaparecem após 2 ou 3 anos. Portanto, o cálculo das emissões de carbono oriundas da degradação florestal é problemático.

Ademais, as florestas naturais apresentam uma dinâmica ainda não totalmente compreendida pelos pesquisadores, e teme-se também que exista dificuldade para a realização das quantificações dos estoques de carbono armazenados nas florestas (árvores vivas, serapilheira e solos, entre outros), bem como o monitoramento contínuo.

Outra dificuldade apontada trata-se do monitoramento e vazamento dos projetos, ou seja, como garantir a medição das taxas de desmatamento do país, da região e dos limites dos projetos, garantindo uma confiabilidade adequada e, principalmente, uma padronização entre os projetos propostos. Também como seria realizada a avaliação do vazamento nessas áreas, tendo em vista que seria muito difícil medir a influência de um projeto REDD na expansão de novas frentes de desmatamento e degradação florestal.

Conforme Kohll et al. (2009) as estimativas de geração de créditos de carbono em projetos REDD podem ser críticas se não for adotado um princípio de conservadorismo e atrelados a estes os respectivos erros associados a um processo de simulação, geralmente não adotados nos projetos. Estes autores afirmam que através de concepções teóricas e muitas vezes simuladas de dados, as estimativas de carbono podem superar os esforços em reduzir o desmatamento e a degradação florestal. Citam ainda que em situações onde os erros nas estimativas não são conhecidos ou estimados, pode-se resultar em uma situação de que uma pequena parte dos créditos projetados inicialmente, efetivamente sejam gerados pelo projeto.

Sabe-se também que em muitas regiões do país existem problemas com questões de documentação e grilagem de terras. Existe uma grande expectativa, por parte do investidor, de que o recurso seja aplicado em projetos que realmente sejam implementados e que possam dar garantias de permanência deles, ou seja, de que o projeto cumprirá seu papel pelo tempo determinado.

Preocupações também têm sido atribuídas à questão social desses projetos. A grande preocupação acerca desse tema é que os benefícios possam chegar também às populações tradicionais, como povos indígenas e extrativistas, de forma a estimular que eles continuem exercendo um papel fundamental na conservação das florestas.

Desse modo, pode-se perceber que ainda são muitas as incertezas que precisam ser bem compiladas antes do desenvolvimento em escala desse tema em nosso país, apesar do objetivo nobre a que o tema se propõe.

\section{Alguns investimentos em projetos REDD}

Existem alguns exemplos de investimentos realizados em projetos de REDD, sendo principalmente transações através de mercados informais, fundos específicos movidos por doações voluntárias e iniciativas atreladas em mercados. Contudo, pode-se perceber que as incertezas ainda são grandes para o desenvolvimento desses projetos.

A ONU, através do Programa UN REDD (fundo multilateral), que fica sob a guarda do Banco Mundial, recebeu uma doação da Noruega no valor de US\$ 51,8 milhões. A Dinamarca demonstrou interesse em efetivar uma doação de US\$ 2 milhões.

O governo da Noruega doou US\$100 milhões ao Fundo Amazônia em agosto de 2008, como parte de um pacote maior que, conforme foi divulgado, poderia alcançar US\$ 1 bilhão, dependendo do desempenho do Brasil na redução do desmatamento e das emissões de GEE associadas.

Conforme anunciado pelo governo, o fundo pretende arrecadar até US\$ 21 bilhões em doações, principalmente de fontes internacionais. Reduções de desmatamento alcançadas durante a gestão do fundo 
gerariam certificados de carbono, que não seriam negociáveis em mercados e, portanto, não poderiam ser usados como compensação para emissões em países industrializados (ANDERSON, 2009).

O que predomina, principalmente nos projetos recentes, são acordos bilaterais para a viabilização das iniciativas de projetos REDD, como por exemplo os projetos Juma e Genesis, entre outros.

Conforme exposto por TFG (2010), muitos países se comprometeram em Copenhague a gastar 3,5 bilhões de dólares durante o período 2010-2012 com projetos REDD+. Não há nenhum registro formal desses compromissos, apesar de vários governos e ONGs terem solicitado um registro dos compromissos assumidos. Após a reunião de Paris, em março de 2010, o total de promessas de doação para o REDD+, de acordo com relatos, atingiu o montante de 4,9 bilhões dólares para os três anos, com novos compromissos assumidos pela Espanha, Alemanha e Eslovênia. Esses compromissos estão resumidos a seguir (em ordem decrescente de tamanho):

- Noruega: o compromisso de financiamento presume-se ser entre 1 e 1,5 bilhões de dólares para esse período. Há alguma variação entre os relatórios (o Presidente da Noruega disse na COP-15 US\$ 1 bilhão para os três anos, mas a Noruega prometeu anteriormente até US\$ 0,5 bilhão por ano). O TFG acredita que US\$ 1 bilhão durante os três anos está realmente previsto para desembolso;

- Estados Unidos: prometeram US\$ 1 bilhão para 2010-2012 (US\$ 233 milhões propostos para 2010 e US\$ 347 milhões para 2011);

- Austrália: se comprometeu a gastar até US\$ 626 milhões nos 3 anos (US\$ 243 milhões em 2010, US\$ 243 milhões em 2011 e US\$ 140 milhões em 2012, média de US\$ 208 milhões/ano), mas isso não foi confirmado. A Austrália tem atualmente uma Iniciativa de Carbono Florestal de US\$ 273 milhões, mas o prazo para essa iniciativa não é claro (alguns fundos foram prometidos antes de 2010). A Austrália não pôde confirmar a sua promessa ou fornecer detalhes adicionais em uma troca de e-mail;

- Japão: é relatado que o país tenha oferecido US\$ 500 milhões (US\$ 167 milhões/ano). Não foram encontradas informações sobre os planos do Japão e a promessa não foi confirmada;

- Reino Unido: prometeu US\$ 450 milhões (cerca de US\$150 milhões/ano);

- Comissão Europeia: prometeu US\$ 380 milhões (estimativa de US\$ 127 milhões/ano);

- França: prometeu US\$ 336 milhões (aproximadamente US\$ 112 milhões/ano);

- Espanha: anunciou US\$150 milhões (US\$ 50 milhões/ano);

- Alemanha: anunciou US\$ 118 milhões (US\$ 39 milhões/ano);

- Eslovênia: anunciou US\$ 12 milhões (US\$ 4 milhões/ano).

Dessa forma, percebem-se ainda muitas iniciativas de financiamentos voluntários para projetos REDD sem uma regulamentação de metodologia de linha de base e de monitoramento aprovadas para a condução dos mesmos.

No caso das ações que estão sendo desenvolvidas no Brasil, percebe-se que elas são focadas em grande parte nesses mercados voluntários, tomando assim um foco diferente daquele pretendido pelo governo brasileiro, que tem a intenção de apoiar atividades e projetos que se enquadrem no Fundo Amazônia, sendo o recurso gerido pelo governo.

\section{CONCLUSÕES}

- Após análise do cenário exposto, pode-se concluir que as incertezas sobre a redução de emissões do desmatamento e da degradação florestal ainda são muitas, assim como os interesses dos atores envolvidos nessa questão em nosso país.

- Existem muitas iniciativas positivas em todo o mundo, cada uma com suas particularidades, entretanto, esse assunto ainda carece de mais subsídios técnicos, regulatórios e econômicos, para que passe a ser encarado como uma alternativa viável para a remuneração pelos serviços prestados pelas florestas para as alterações climáticas do planeta.

- Tecnicamente, há muito em que se avançar sobre a geração de estimativas e fatores confiáveis sobre a dinâmica das florestas nativas nas diferentes ecorregiões, principalmente pela escassez de informação sobre essa dinâmica ao longo de ciclos mais longos.

- Conclui-se também que os avanços das negociações sobre o tema junto ao UNFCCC são de primordial importância para que as iniciativas e discussões sobre REDD não percam sua força antes mesmo de ter tido a chance de contribuir para o combate das mudanças climáticas. Com a sua 
inclusão formal em um acordo internacional sobre o tema, haverá uma padronização sobre procedimentos, que deverá contribuir para que esse novo mecanismo possa contribuir para as mudanças climáticas.

\section{REFERENCIAS}

AGÊNCIA EUROPEIA DO AMBIENTE (AEA). Sinais da AEA - Questões Ambientais Chave para a Europa. Não apenas ar quente - Diplomacia global e a procura de um sucessor para o Protocolo de Quioto. Luxemburgo: Serviços das Publicações Oficiais das Comunidades Europeia. 2009. 40 p.

ANDERSON, A. B. Redução de Emissões Oriundas do Desmatamento e Degradação Florestal (REDD): Desafios e Oportunidades. Mudanças Climáticas. Andi. 2009. Site: http://www.mudancasclimaticas. andi.org.br/. Acesso em: 01/02/2010.

ANGELSEN, A. Moving Ahead with REDD - Issues, Options and Implications. Indonesia: CIFOR, 2008. $156 \mathrm{p}$.

CCBAA - THE CLIMATE, COMMUNITY AND BIODIVERSITY ALLIANCE. Acesso: Clima, Comunidade e Biodiversidade. Padrões para Concepção de Projetos. Segunda Edição em Português. Arlington, VA. Dezembro, 2008. Em: www.climatestandards.org.

CENAMO, M.; PAVAN, M. N.; CAMPOS, M. T.; BARROS, A. C.; CARVALHO, F. Casebook of REDD Projects in Latina America. 1st Edition. Manaus, 2009. 80 p.

CENAMO, M. Projeto de RED da RDS do Juma recebe "Status Ouro" em validação do CCBAA. Fonte: $<$ http://www.idesam.org.br/noticias/Artigo\%20Site\%20IDESAM\%2022\%20out.pdf〉. Acesso em: $04 / 01 / 2010$.

CENTRO INTERNACIONAL DE PESQUISA FLORESTAL (CIFOR). Simplesmente REDD. Guia do CIFOR sobre Florestas, Mudanças Climáticas e REDD. 2008. 16 p.

The context of REDD+ in Brazil: Drivers, agents and institutions. 2. ed. Indonesia. 2011. 88 p.

CORTE, A. P. D. Metodologia para detecção de mudanças em projetos de redução de emissões do desmatamento e da degradação florestal (REDD). 165 p. Tese do Curso de Pós-Graduação em Ciências Florestais da Universidade Federal do Paraná. (Doutorado em Ciências Florestais). 2010.

FOOD AND AGRICULTURE ORGANIZATION (FAO) Global forest resource assessment 2005: towards sustainable forest management. Roma, 2005. $351 \mathrm{p}$.

KOHLL, M.; BALDAUF, T.; PLUGGE, D.; KRUG, J. Reduced emissions from deforestation and forest degradation (REDD): a climate change mitigation strategy on a critical track. Carbon Balance and Management. 2009. v. 4, n. 10. p. 1 - 10.

INPE - Instituto Nacional de Pesquisas Espaciais. Deforestation estimates in the Brazilian Amazon. São José dos Campos: Web-site: http://www.obt.inpe.br/prodes/prodes_1988_2008.htm. Acesso em: 10/12/2008.

MINISTÉRIO DE CIÊNCIA E TECNOLOGIA MCT -. Primeiro Inventário Brasileiro de Emissões Antrópicas de Gases de Efeito Estufa. Brasília. 2004. 86 p.

MOUTINHO, P.; SCHARTZMAN, S. Tropical deforestation and climate change. IPAM - Instituto de Pesquisa Ambiental da Amazônia e Environmental Defense. Belém, 2005. 132 p.

PARKER, C.; MITCHELL, A.; TRIVEDI, M.; MARDAS, N. The Little REDD Book. Global Canopy Foundation. Oxford. 2008. 112 p.

TROPICAL FOREST GROUP TFG -. Oportunidades de financiamento para REDD+ nos Estados/Províncias membros do GCF. 07 de maio de 2010. 17 p.

UNITED NATIONS FRAMEWORK CONVENTION ON CLIMATE CHANGE (UNFCCC) -. Protocolo de Quioto: A convenção sobre mudança no clima. Versão traduzida pelo Ministério da Ciência e Tecnologia. 2004. 29 p. Disponível em: <http://www.mct.gov.br/Clima/quioto/protocol.htm>. Acesso em: 16 agosto de 2011.

WERTZ-KANOUNNIKOFF, S.; KONGPHAN-APIRAK, M. Emerging REDD+. A preliminary survey of demonstration and readiness activities. CIFOR. Working paper $n^{\circ} 46$. Indonesia. 2009. $44 \mathrm{p}$. 